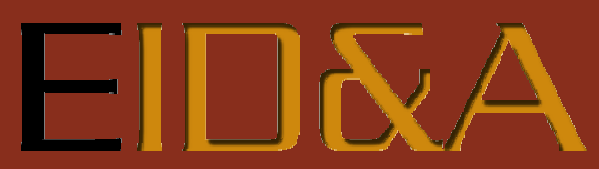

Revista Eletrônica de Estudos Integrados em Discurso e Argumentação

http://dx.doi.org/10.17648/eidea-15-1881

\title{
RETÓRICA DO PRECONCEITO: UMA ANÁLISE DE DISCURSOS SOBRE VOZES MARGINAIS
}

\author{
Carlos Piovezani ${ }^{i}$ \\ Thiago Barbosa Soares
}

Resumo: Nosso objetivo, a partir da Análise do discurso derivada dos trabalhos de Michel Pêcheux, consiste em apontar sumariamente alguns sentidos diversos atribuídos à voz humana, para apresentar certos consensos e identificar os argumentos que fundamentam os discursos eufóricos e disfóricos sobre a voz humana em discursos cuja voz seja objeto. Assim, buscamos responder à seguinte questão: quais são as relações dos dizeres antigos com os dizeres modernos que depreciam as falas popular e feminina? Para tanto, analisamos recortes de textos da literatura, da filosofia, da oratória e da mídia que apontam para vozes e sobre as quais tecem comentários que são analisados e cotejados com vistas a se evidenciar estigmas e preconceitos atribuídos à voz das massas populares e aos traços vocais femininos.

Palavras-chave: Voz. Discurso. Retórica. Preconceito.

Abstract: Our objective, based on the branch of Discourse Analysis derived from the works of Michel Pêcheux, is to summarize a few different meanings attributed to the human voice, to present certain consensuses and to identify the arguments that support the euphoric and dysphoric discourses on the human voice in speeches whose voice is an object. Thus, we try to answer the following question: which relations are there between the old and the modern sayings that depreciate the popular and the feminine voices? In order to do so, we analyze excerpts of texts from Literature, Philosophy, Oratory and the media that point to voices and comment about them. These excerpts are, then, analyzed and compared in order to show stigmas and prejudices attributed to the voice of the popular masses and the female vocal traits.

Keywords: Voice. Discourse. Rhetoric. Prejudice.

\footnotetext{
' Professor doutor do Programa de Pós-Graduação em Linguística da Universidade Federal de São Carlos (UFSCar), Brasil. E-mail: cpiovezani@hotmail.com.

ii Professor da Universidade Federal de Tocantins (UFT) e doutorando em Linguística pela Universidade Federal de São Carlos (UFSCar), Brasil. E-mail: thiagobsoares@bol.com.br.
} 
EID\&A - Revista Eletrônica de Estudos Integrados em Discurso e Argumentação, Ilhéus, n. 15, jan./jun.2018.

\section{Introdução}

A boa ficção nos fornece muito frequentemente importantes choques de realidade e valiosas matérias para os sonhos. Nela nos defrontamos com as propriedades e transformações das relações entre os homens e de suas diversas condições sociais. Não raras vezes é também na literatura que descobrimos aspectos interessantes do papel desempenhado pela linguagem no estabelecimento dessas relações e condições. Tudo isso já nos foi ensinado pela própria literatura, por produtivos estudos linguísticos e pela fortuna crítica de reconhecidos autores. Talvez os textos ficcionais sejam mais discretos quanto à presença e às funções da voz humana na constituição dos encontros e dos confrontos entre os sujeitos de uma sociedade. A crítica literária e as práticas de ensino da língua e da literatura consideraram-nas bem mais raramente. Cremos que seu exame seja bastante proveitoso, visto que a relativa discrição de que falamos não corresponde à sua inexistência nem a uma sua importância menor.

Com efeito, a voz cumpre um papel fundamental na construção da magia da aristocrática montanha retratada por Thomas Mann, principalmente na memória de Hans Castorp em cujas lembranças afetivas ressoam "aquela voz agradável, velada e um tanto rouca" de Pribislav Hippe e de Cláwdia Chauchat ${ }^{1}$. Sua função não é menor no sofrimento das gentes pobres das periferias indigentes, de que fala Albert Camus. Em ambos atribui-se à voz uma considerável importância na instauração da consistência e do esgarçamento dos laços sociais. Nem por isso, contudo, dizem exatamente algo idêntico sobre a voz nem tampouco tratam das mesmas condições de produção. Longe dos Alpes e também distante do subúrbio da Argélia, seja num confim operário do Rio de Janeiro seja num ponto do sertão nordestino, não se deve descurar da importância da voz no exame da composição narrativa, das relações sociais e afetivas.

Portanto, não são evidentes os efeitos de sentidos que recaem sobre os enunciados cuja voz é objeto de observação; razão pela qual se faz importante a investigação dos dizeres sobre a voz em diversos campos do conhecimento. Assim, norteados pela indagação: quais são as relações dos dizeres antigos

${ }^{1}$ Hans Castorp distinguiu com interesse a voz velada de Mme Chauchat. Como sempre, quando avistava aquela mulher negligente, sentia reafirmar-se aquela semelhança que andara procurando por tanto tempo e finalmente descobrira num dos seus sonhos... (MANN, 1952, p. 142). Em todo caso, devotava-lhe um interesse especial e, ao dirigir-se à escola, já se regozijava com a ideia de observá-lo no trato com os companheiros de curso, de vê-lo falar e rir-se, e de distinguir-lhe de longe a voz no meio das outras, aquela voz agradável, velada e um tanto rouca. (Ibidem, p. 148) 
EID\&A - Revista Eletrônica de Estudos Integrados em Discurso e Argumentação, Ilhéus, n. 15, jan./jun.2018.

com os dizeres modernos que depreciam as falas popular e feminina, analisamos adiante fundamentamos teórica e metodologicamente na Análise do discurso derivada de Michel Pêcheux e seu grupo, uma série de enunciados extraídos de um corpus constituído por recortes de textos da literatura, da filosofia, da oratória e da mídia.

Para Pêcheux $(1990 ; 1997)$ as constantes lutas de classes e as demais relações de força que se processam no interior de uma sociedade materializam-se em ideologias, que, por sua vez, manifestam-se em práticas, entre as quais as práticas discursivas desempenham um papel privilegiado nessa materialização ideológica. A história das lutas sociais não apenas estará refletida nos textos que produzimos, mas também, e, sobretudo, os constituirá no próprio âmago de suas formulações, nas quais se efetivam os discursos. A esse fenômeno Orlandi (1998, p.54) denominou "historicidade do texto". A série de recortes que reproduzimos logo abaixo demonstra a historicidade do que se pode chamar de uma espécie de retórica do preconceito acerca das vozes popular e feminina.

\section{Um coro de diversas vozes}

Sabemos que em Vidas Secas o silêncio, a língua e a voz são determinantes nos encontros e confrontos de Fabiano com seu Tomás da bolandeira, com o patrão atual e consigo mesmo, nos quais se destacam sua revolta, mas principalmente a dominação que se lhe impõe:

- Fabiano, você é um homem, exclamou em voz alta.

Conteve-se, notou que os meninos estavam perto, com certeza iam admirar-se ouvindo-o falar só. E, pensando bem, ele não era homem: era apenas um cabra ocupado em guardar coisas dos outros. [...] como vivia em terra alheia, cuidava de animais alheios, descobria-se, encolhia-se na presença dos brancos e julgavase cabra.

Olhou em torno, com receio de que, fora os meninos, alguém tivesse percebido a frase imprudente. Corrigiu-a, murmurando:

- Você é um bicho, Fabiano. (RAMOS, 1997, p. 18)

O patrão atual, por exemplo, berrava sem precisão. Quase nunca vinha à fazenda, só botava os pés nela para achar tudo ruim. O gado aumentava, o serviço ia bem, mas o proprietário descompunha o vaqueiro. Natural. Descompunha porque podia descompor, e Fabiano ouvia as descomposturas com o chapéu de couro debaixo do braço, desculpava-se e prometia emendarse. Mentalmente jurava não emendar nada, porque estava tudo em ordem, e o amo só queria mostrar autoridade, gritar que era dono. Quem tinha dúvida? (Ibidem, p. 22-23) 
EID\&A - Revista Eletrônica de Estudos Integrados em Discurso e Argumentação, Ilhéus, n. 15, jan./jun.2018.

O corpo, a voz e a alma de Fabiano são espezinhados pelo soldado amarelo, que the dá dois empurrões, que lhe dirige a fala aos brados e 0 insulta, ao passo que ele afirma estar quieto, gagueja e engasga-se; vai para a cadeia, ouve a acusação que não entende, apanha e é aprisionado. Fabiano revolta-se e sofre em silêncio: "Sabia perfeitamente que era assim, acostumara-se a todas as violências, a todas as injustiças." (RAMOS, 1997, p. 33). Violências e injustiças dessas e de outras ordens também ocorrem em outras periferias em que habitam as gentes das camadas sociais mais desprovidas.

Deixando por ora em suspenso as referências literárias à voz humana e partindo do pressuposto de que, na construção discursiva das virtudes dos sujeitos de um grupo, de uma classe ou de uma comunidade, produz-se direta e/ou indiretamente a atribuição dos estigmas imputados a outros que thes sejam exteriores e/ou estranhos, pretendemos apresentar aqui algumas formulações que, produzidas principalmente no interior da Retórica e da Mídia, parecem atestar certos consensos sobre a voz popular e feminina ${ }^{2}$. Trata-se aqui de uma constância da diferença entre a precisão e sofisticação dos cultos e a incivilidade e suscetibilidade dos iletrados, de um lado, e entre a energia do gênero masculino e a frouxidão do feminino, de outro, que não mais deveria frequentar esses e outros campos de saber de nossas sociedades contemporâneas.

Se as acepções em verbetes de dicionários de diversas épocas e lugares já nos dão indícios da heterogeneidade dos sentidos atribuídos à voz (cf. PIOVEZANI, 2016), em passagens de textos de outros gêneros e campos do conhecimento somos confrontados com uma sua ainda maior diversidade. Em tais excertos as dimensões articulatória e acústica encontram-se mais ou menos presentes, mas estão praticamente subsumidas em funcionamentos de outra natureza e alcance. Seja na retórica, seja nas ciências naturais ou ainda na literatura e na filosofia, a voz tornou-se objeto de discurso, sendo em princípio focalizada sob ângulos bastante diversos:

Quanto à pronúncia, ela possui uma eficácia e um poder surpreendentes no discurso: a qualidade do que nós compusemos em nosso espírito importa menos do que a maneira pela qual nós o exprimimos. Com efeito, a emoção do interlocutor depende do que ele ouve. [...] Toda ação comporta dois elementos, a voz e o gesto, que agem um sobre os olhos e a outra sobre os ouvidos; ou seja,

\footnotetext{
${ }^{2}$ Em A voz do povo, Courtine (2015) reflete sobre os preconceituosos rótulos com que se classificam as vozes populares e sobre as estratégias para silenciá-las.
} 
EID\&A - Revista Eletrônica de Estudos Integrados em Discurso e Argumentação, llhéus, n. 15, jan./jun.2018.

os dois sentidos pelos quais toda impressão penetra na alma. É preciso falar antes da voz, à qual mesmo o gesto está subordinado. (QUINTILIANO, 2003, p. 230)

Em algumas espécies de quadrúmanos existe uma grande diferença entre machos e fêmeas adultos, relacionada com o timbre e a intensidade da voz, e com o desenvolvimento dos órgãos vocais. O homem parece ter herdado de seus ancestrais essa diferença. Em comparação com as cordas vocais de mulheres e das crianças, as do homem adulto são cerca de um terço mais compridas. (DARWIN, 2004, p. 499)

A voz é o nome desse elemento, cuja fenomenalidade não corresponde a algo mundano. Escuta-se a voz. Os signos fônicos são "ouvidos" pelo sujeito que os profere na proximidade absoluta de sua presença. O sujeito não precisa sair de si para ser imediatamente afetado por sua atividade de expressão. Minhas falas são "vivas", porque elas parecem não me deixar: não parecem cair fora de mim, fora de meu sopro, num distanciamento visível; elas não cessam de me pertencer, de estarem à minha disposição, sem acessório. Assim se dá, em todo caso, o fenômeno da voz, a voz fenomenológica. (DERRIDA, 1967, p.85)

A enunciação e a instância de discurso não são identificáveis como tais senão através da voz que as profere, e, somente supondo nelas uma voz, algo como um ter-lugar do discurso pode ser mostrado. [...] A voz situa-se em uma dimensão ontológica fundamental. [...] assim considerada, mostrar-se-á como pura intenção de significar, como puro querer-dizer, no qual alguma coisa se dá à compreensão sem que se produza ainda um evento determinado de significado. (AGAMBEN, 1985, p. 52-53)

Nas Instituições oratórias, de Quintiliano, encontramos a descrição dos componentes vocais, a prescrição de como o orador se deve servir da voz na expressão distinta de cada paixão e a indicação da sedução exercida por ela e do sucesso que se pode obter por seu uso, no primeiro; e a reiteração dessa sedução e desse poder, que ultrapassam as forças do verbo e do gesto, no segundo. Já em $A$ origem do homem, de Charles Darwin, assinalam-se as diferenças entre i) a extensão das cordas vocais e a potência da voz nas mulheres e crianças, de um lado, e nos homens, de outro; ii) a masculinidade e a maciez; iii) o vigor e o falsete; iv) a emissão sedutora e a escuta seduzida; e v) a língua materna e desenvolta e a voz potente. Por fim, enquanto, em A voz e o fenômeno, de Jacques Derrida, observamos uma crítica a um dos traços da razão ocidental, que faz corresponder a elocução da voz à presença e à existência imediata do ser, em A linguagem e a morte, de Giorgio Agamben, indica a condição negativa da voz humana. Ora, para esse último a voz já não é mais o equivalente a um ruído qualquer ou aos sons fonéticos produzidos por outros animais, mas que ainda não é em si a linguagem duplamente articulada, 
EID\&A - Revista Eletrônica de Estudos Integrados em Discurso e Argumentação, Ilhéus, n. 15, jan./jun.2018.

que combina segmentos sonoros destituídos de significação, cuja soma regulada por regras da língua produz unidades dotadas de sentido.

Após nossa breve exposição de certos aspectos da diversidade encontrada em enfoques e sentidos da voz e da heterogeneidade dos enunciados que a tematizam, de seus enunciadores e dos campos e gêneros discursivos em que se inserem, buscaremos, a seguir, exibir algumas regularidades que se conservam longamente nos discursos sobre a voz humana. Direta e indiretamente a reiteração de alguns desses dizeres sobre a voz não apenas contribui para a perpetuação de estigmas, mas mais fundamentalmente os constitui, seja tratando dos vícios das vozes dos falantes de certos grupos seja mencionando as virtudes das produções vocais de determinados falantes de algumas outras comunidades.

\section{Vozes populares e femininas, vozes difamadas}

Fundamentados no pressuposto de que, a despeito da onipresença da atividade epilinguística na fala humana, ou seja, da faculdade que faz com que constantemente falemos de nossa própria fala, a voz não está com frequência presente em nosso dizer sobre ela mesma. Em vista disso, avançamos a suposição de que a rarefeita emergência de discursos sobre a voz tende a ser contrafeita em ocasiões em que pese sobre ela perigos reais ou imaginários e/ou nas quais ela concentre em si algum poder mais ou menos considerável (PIOVEZANI, 2011; 2014).

Em Aristóteles, encontramos a afirmação de que "os oradores incultos persuadem melhor as massas populares do que os ilustrados; os incultos são mais bem versados na arte de falar diante das multidões" (ARISTÓTELES, 2002, p. 39). Ainda segundo o filósofo grego, isso também ocorreria, "porque enquanto aqueles, os ilustrados, formulam proposições unânimes e gerais, estes, os incultos, enunciam proposições que são conhecidas de seu auditório". (ARISTÓTELES, 2002, p. 39). Diante desse parecer retóricodiscursivo, não nos parece ser exagero ver no artigo de Ruth de Aquino, publicado aos 30 de março de 2012 na revista Época, os ecos e a perpetuação desse antigo preconceito sobre a voz e a escuta dos oradores e dos auditórios populares ${ }^{3}$ :

\footnotetext{
${ }^{3}$ Em Piovezani (2015) discorremos sobre esses preconceitos em relação à fala popular, em geral, e à voz de Lula, em particular.
} 
EID\&A - Revista Eletrônica de Estudos Integrados em Discurso e Argumentação, llhéus, n. 15, jan./jun.2018.

\begin{abstract}
Mais uma gafe
O presidente que cometeu mais gafes na história do Brasil conseguia quase sempre roubar a cena ao abrir a boca. [...] Sua voz rouca, com erros de português, metáforas de futebol e piadas do povão, era o elo com a massa, na versão sindicalista exaltado ou do lulinha paz e amor. O Brasil teve outros oradores inflamados [...] [que] se expressavam com vigor também na escrita. Lula não. Exerce uma liderança oral. A maioria da população brasileira não domina a palavra escrita. [...] Num país assim, a voz é hipervalorizada como capital simbólico. Lula sempre falou demais.
\end{abstract}

Aos preconceitos de classe, que se constroem seja pela euforia com que se caracterizam uns ("correto, límpido, elegante e bem adaptado"; "a ação oratória será correta, ou seja, sem defeitos, se a emissão da voz for fácil, nítida, agradável, bem romana") seja pela disforia atribuída a outros ("sotaque campesino" ou "estrangeiro"; "gafes"; "erros de português, metáforas de futebol e piadas do povão"; "A maioria da população brasileira não domina a palavra escrita"; "Lula sempre falou demais") e por seu direto ou indireto cotejamento, somam-se os de outras ordens. Portanto, para esses fatores não existem triagens puras nem fronteiras intransponíveis e bem estabelecidas que pudessem isolar ou enfraquecer os julgamentos que enobrecem ou difamam a língua e a voz de seus falantes; ocorre o inverso: a condição socioeconômica incide sobre os níveis de instrução, que também incidem sobre a pertença às classes sociais. Esses elementos e a instrução incidem sobre as procedências regional e/ou étnica, que, por sua vez, não passam ilesas pelos gêneros masculino e feminino.

$\mathrm{Na}$ construção e na conservação dos preconceitos acerca da voz, além da conveniência das clivagens e dos liames, funcionam as idealizações, uma vez que, de modo análogo ao que acontece com as avaliações e autoavaliações dos usos linguísticos em geral, há superestimação das supostas correções e subestimação dos pretensos defeitos dos usos próprios e alheios da voz. Há forte tendência de superestimação entre os que julgam dominar a chamada norma culta e de subestimação entre os que julgam não a dominar. Conjuga-se contraditoriamente com esse funcionamento aquele segundo o qual se atribui o sotaque à voz do outro e o "grau zero" da pronúncia à própria voz. Tal modo de proceder parece estender-se até as bastante excepcionais ocasiões em que ouvimos nossa própria voz, numa escuta intermediada por sua gravação e por sua reprodução em aparelhos tecnológicos. Se as triagens e as misturas desempenham importantes papeis na exaltação e na difamação de línguas, falas e vozes dos diversos segmentos de uma sociedade, elas não atuam nesse espaço em constante equilíbrio. Nas 
EID\&A - Revista Eletrônica de Estudos Integrados em Discurso e Argumentação, llhéus, n. 15, jan./jun.2018.

avaliações das diferenças entre as vozes masculinas e femininas, as misturas parecem estar interditadas. Nesse domínio, a consagração e o descrédito são produzidos principalmente, ainda que não exclusivamente, por separações que se pretendem absolutas e definitivas.

Já num período pós Revolução francesa, do outro lado do Canal da Mancha, a obra de Darwin desvencilha-se do fundamento teológico, onipresente na retórica religiosa, mas não deixa de reafirmar enfaticamente a distinção masculino/feminino na voz dos animais e sua função capital na seleção sexual e na evolução das espécies (cf. SALAZAR, 2008; glosamos aqui a ideia contida nesse seu texto). Observemos abaixo algumas passagens de sua obra $A$ origem do homem e a seleção sexual:

\footnotetext{
Em algumas espécies de quadrúmanos existe uma grande diferença entre machos e fêmeas adultos, relacionada com o timbre e a intensidade da voz, e com o desenvolvimento dos órgãos vocais. O homem parece ter herdado de seus ancestrais essa diferença. Em comparação com as cordas vocais de mulheres e das crianças, as do homem adulto são cerca de um terço mais compridas. [...]

O orador apaixonado, o bardo, o músico, quando com seus tons variados e suas cadências excitam as mais fortes emoções em seus ouvintes, provavelmente estarão usando o mesmo meio pelo qual, num período extremamente remoto, seus ancestrais semi-humanos despertaram uns nos outros ardentes paixões, enquanto se empenhavam em cortejar o sexo oposto ou em desafiar seus rivais. (DARWIN, 2004, p. 503-504)
}

Já no século XXI, depois de revoluções comportamentais, entre as quais se destacam a consolidação do feminismo e a efervescência da teoria e da cultura queer, do lado leste e do lado oeste do Atlântico, vimos por aqui novas e renitentes manifestações conservadoras da mídia nacional de grande circulação. Essas manifestações costumeiramente provêm de discursos antiprogressistas em cujo funcionamento verificamos uma "retórica reacionária" (ANGENOT, 2015, p. 101-125), constituída pelos argumentos da "inocuidade", do "efeito perverso", do "risco" e "derrocada fatal" ante demandas e conquistas igualitárias.

Diante da aventura inócua, perversa, arriscada e até letal dos progressos sociais, a retórica reacionária reage em nome de uma segurança econômica, salutar, garantida e conservadora. Porém, nem só dessa grave segurança vivem os discursos reacionários; eles podem se materializar em enunciados que produzem efeitos leves e bem-humorados. Em muitas condições nas quais os gêneros tradicionais das doutrinas podem parecer carrancudos, o humor 
EID\&A - Revista Eletrônica de Estudos Integrados em Discurso e Argumentação, llhéus, n. 15, jan./jun.2018.

pode expandi-la e consolidá-la por outros e mais eficazes meios. Assim, reiteram-se e consolidam-se pesados e preconceituosos consensos com a leveza de uma blague e a amenidade de um sorriso. A tentativa é a de afastar, quando não de eliminar, a pertinência e a legitimidade das reivindicações igualitárias mais prementes, imputando-lhes o estigma do radicalismo, que por supostamente serem descabidos e ridículos apenas podem tornar-se objeto de humor. É o que ocorre numa reportagem sobre o grupo feminista Femen publicada na edição do dia 29 de dezembro de 2013 da Folha de São Paulo. Ao título "Como se forma uma Femen", seguem os seus assim chamados "Mandamentos do Femen", entre os quais podemos ler o seguinte:

Protestar com voz firme e alta ${ }^{4}$

A cara deve ser sempre de indignação, para refletir o sentimento do movimento sobre os temas contra os quais protestam. A voz, firme e alta. Sorrir, jamais.

O descrédito do movimento se constrói ali a partir da referência a seus "Mandamentos", o que lhe atribui a pecha do dogmatismo, mas também com a possível equivalência entre "voz firme e alta" das integrantes do Femen de hoje e a estridência dos gritos das histéricas de ontem; com o registro linguístico baixo e o estilo informal de linguagem observados no núcleo do sintagma "A cara"; e com o radicalismo emblemática e ludicamente apresentados nos advérbios ali empregados "sempre" e "jamais". Não é exatamente com maior consideração que são tratadas a condição feminina e a voz da mulher em outro texto da Folha.

Outras marcas linguísticas do texto que transcrevemos integralmente abaixo fazem deslizar os sentidos para outra direção.

Eles e ela $a^{5}$

Em uma reunião das frentes parlamentares ligadas à saúde, a deputada Alice Portugal ( $P C$ do $B$ ) lutava para discursar, enquanto colegas falavam alto em conversas paralelas. No comando dos trabalhos, o presidente da Frente das Santas Casas, Antonio Britto (PTB), chamou a atenção dos presentes. E o ministro da Saúde, Alexandre Padilha, pegou carona: 'É a primeira mulher a falar, vamos respeitar...' Meio sem jeito, a deputada se justificou: 'É a falta de testosterona na voz. Mas o importante é que os eleitores do meu Estado me ouvem sempre!'

\footnotetext{
${ }^{4}$ Caderno Mundo da FSP, 29 de dezembro de 2013.

${ }^{5}$ Painel, caderno Poder da FSP, 19 de março de 2011.
} 
Se, por um lado, o relato foi publicado no caderno Poder, por outro, o foi sob a forma de uma anedota, em sua sessão "Painel", reconhecidamente de menor importância editorial. O polissêmico título "Eles e ela" menos sinaliza para a desproporção entre pares do que tende a se estabilizar ao ser possivelmente parafraseado com as locuções "Meio sem jeito" e "se justificou" relacionadas aos comportamentos da deputada. O que fundamenta tais seleções lexicais que precedem, emolduram e direcionam o discurso direto de Alice Portugal? Antes de dar voz direta à personagem central do episódio, não poderia o enunciador ter empregado algo como "A parlamentar reagiu com indignação que deveria ser a de todas nós ao desrespeito com que era tratada e ainda dispensou a bem-intencionada intervenção de seus colegas com os seguintes termos:" para introduzir a fala de Alice Portugal e para, com isso, inscrever-se em outra posição e produzir outros efeitos? Ademais, o relato é construído numa higienizada e distanciada delocução e a expressão cristalizada "pegou carona" somente é ali utilizada porque se coaduna com a condição de um gracejo veiculado na sessão "Painel” conferida ao caso.

Por fim, parece-nos produtivo destacar certos aspectos do enunciado da própria deputada: "É a falta de testosterona na voz. Mas o importante é que os eleitores do meu Estado me ouvem sempre!". O desrespeito e a desatenção de seus colegas diante de sua intervenção seriam devidos à "falta de testosterona na voz", ou seja, a insuficiências relativas à altura de seu volume vocal, à gravidade de sua qualidade de voz, ao vigor de sua dinâmica de fala e à tensão de seu aparelho fonador. Com algum exagero, se poderia afirmar que nessa direção tudo se passa quase como se a deputada dissesse que estava de saia curta... O "Mas" na articulação das duas frases de seu enunciado não é muito menos lamentável e aponta para a equivalência e o encadeamento evidentes, produzidos por um discurso sobre os gêneros masculino e feminino e sobre a voz de seus falantes, entre a força viril da voz e a atenção e respeito da escuta.

\section{Considerações: A escuta de outras vozes}

Vimos que os constantes e intensos elogios à voz formulados pelos retores antigos podem ser interpretados como um julgamento e uma condenação da fala dos "oradores incultos" e da escuta das multidões "iletradas". Como sabemos, esses julgamento e condenação não ficaram no passado; seus ecos e reatulizações constantes continuam a ser decisivos para 
EID\&A - Revista Eletrônica de Estudos Integrados em Discurso e Argumentação, llhéus, n. 15, jan./jun.2018.

macular e deslegitimar as lutas e reivindicações feitas por vozes que trazem em suas forma e substância sonoras as marcas das classes, dos gêneros, das idades e dos lugares quase sempre sem reconhecimento e privados de prestígio. Ao ouvirmos a persistência desses ecos e identificarmos sua força e seu alcance em nossos dias, tornam cada vez mais necessária a produção de dissidências e dissonâncias nessa harmonia tão perversa.

Aprendemos com Michel Foucault que, dentre outras inquietações produzidas pelo discurso, há a de sua "existência transitória destinada a se apagar sem dúvida, mas segundo uma duração que não nos pertence" (2001, p. 8). Se essa propriedade do discurso assim genericamente descrita já nos perturba, deveríamos muito mais nos afligir com a consistência e a tenacidade do fato de que, quando os homens e as mulheres do bairro pobre conseguem a duras penas ultrapassar o silêncio e falar, com grande frequência "suas vozes apagam-se lentamente, progressivamente" (CAMUS, 1972, p. 276).

Se nos fosse permitida uma ligeira, mas importante retificação às palavras de Camus, na direção das reflexões que fizemos aqui, diríamos que repetida e insistentemente essas vozes não se apagam, mas são apagadas; e seu apagamento não costuma se dar de maneira lenta, mas imediatamente, porque os estigmas que lhes são impingidos perseveram em infamá-las e em deslegitimá-las no próprio átimo da expressão. Portanto, podemos responder a questão: quais são as relações dos dizeres antigos com os dizeres modernos que depreciam as falas popular e feminina, do seguinte modo: denegrir e deslegitimar as vozes populares e femininas. Ora, esse tem sido um expediente histórico discursivo frequentemente empregado, na literatura, passando pela oratória, sobretudo, na mídia, para tolher a manifestação de suas frequentes experiências de dor, de suas ainda insuficientes reivindicações de justiça e de seus raros exercícios de plena emancipação. Em prol da desconstrução dessa retórica acerca das vozes popular e feminina para que essas sejam cada vez menos abafadas e estigmatizadas, é fundamental que o ensino de língua, da literatura e das humanidades, em geral, dedique-se a análises dos discursos que manifesta ou discretamente pretendem denegri-las e calá-las. 
EID\&A - Revista Eletrônica de Estudos Integrados em Discurso e Argumentação, llhéus, n. 15, jan./jun.2018.

\section{Referências}

AGAMBEN, Giorgio. A linguagem e a morte. Belo Horizonte: EdUFMG, 2006.

ANGENOT, Marc. 0 discurso social e as retóricas da incompreensão. Organização e apresentação de Carlos Piovezani. São Carlos: EdUFSCar, 2015.

AQUINO, Ruth de. Mais uma gafe. Revista Época. 30 mar. 2012.

ARISTÓTELES. Rhétorique. Paris: Les Belles Lettres, 2002.

CAMUS, Albert. As vozes do bairro pobre. In: Cadernos de Albert Camus. Vol. II. Escritos da juventude. Lisboa: Livros do Brasil, 1972. p. 260-276.

CÍCERO. De l'orateur. Paris: Les Belles Lettres, 2002.

COURTINE, Jean-Jacques. A voz do povo: a fala pública, a multidão e as emoções na aurora da era das massas. In: ; PIOVEZANI, Carlos. História da fala pública: uma arqueologia dos poderes do discurso. Petrópolis: Vozes, 2015. p. 261-289.

DARWIN, Charles. A origem do homem e a seleção sexual. Belo Horizonte: Itatiaia, 2004.

DERRIDA, Jacques. La voix et le phénomène. Paris: PUF, 1967.

FOLHA DE S. PAULO. São Paulo: Painel, Caderno Poder, 19 mar.2011.

FOLHA DE S. PAULO. São Paulo: Caderno Mundo, 29 dez. 2013.

FOUCAULT, Michel. A ordem do discurso. São Paulo: Loyola, 2001.

MANN, Thomas. A montanha mágica. São Paulo: Círculo do Livro, 1952.

ORLANDI, Eni. Interpretação: autoria, leitura e efeitos do trabalho simbólico. Petrópolis: Vozes, 1998.

PÊCHEUX, Michel. Delimitações, inversões, deslocamentos. Caderno de Estudos Linguísticos. Campinas, v. 19, 1990.

. Análise automática do discurso. In: GADET, Françoise; HAK, Tony (Org.). Por uma análise automática do discurso. Trad. Bethania Mariani et al. Campinas: Ed.Unicamp, 1997.

PIOVEZANI, Carlos. Usos e sentidos da voz no discurso político eleitoral brasileiro. Alfa (Revista de Linguística da UNESP). São Paulo, v. 55, n. 01, p. 163-176, 2011.

. Compreender e desvelar posições e estratégias da mídia com Foucault: uma análise de discursos da imprensa brasileira sobre a voz de Lula. In: ; CURCINO, luzmara; SARGENTINI, Vanice (Org.). Presenças de Foucault na Análise do discurso. São Carlos: EdUFSCar, 2014. p. 175-202. 
EID\&A - Revista Eletrônica de Estudos Integrados em Discurso e Argumentação, Ilhéus, n. 15, jan./jun.2018.

. Falar em público na política contemporânea: a eloquência pop e popular brasileira na idade da mídia. In: COURTINE, Jean-Jacques; PIOVEZANI, Carlos. História da fala pública: uma arqueologia dos poderes do discurso. Petrópolis: Vozes, 2015. p. 290-337.

- Instantâneos de duradouros estigmas: consensos sobre as vozes popular e feminina (da Retórica antiga à mídia contemporânea). In: CURCINO, Luzmara; SARGENTINI, Vanice; PIOVEZANI, Carlos (Org.). (In)subordinações contemporâneas: consensos e resistências nos discursos. São Carlos: EdUFSCar, 2016. p. 73-101.

RAMOS, Graciliano. Vidas Secas. 72.ed. Rio de Janeiro; São Paulo, Record, 1997.

QUINTILIANO. Institution oratoire. Paris: Les Belles Lettres, 2003.

SALAZAR, Philippe-Joseph. Darwin à Padoue: I'anthropologie de la voix au XVIlè et au XIXè siècles. In: CASSIN, Barbara; COHEN-LÉVINAS, DANIELLE (Org.). Vocabulaires de la voix. Paris: L'Harmattan, 2008. p. 39-52.

Forma de citação sugerida:

Piovezani, Carlos; SOARES, Thiago Barbosa. Retórica do preconceito: uma análise de discursos sobre vozes marginais. EID\&A - Revista Eletrônica de Estudos Integrados em Discurso e Argumentação, Ilhéus, n. 15, p. 58-70, jan./jun.2018.

Recebido em: 10/03/2018

Aprovado em: 13/06/2018 